\title{
ANALISIS EFISIENSI KERJA AC JENIS SPLIT WALL DALAM RUANGAN TERTUTUP CV. JAYATAMA
}

\author{
Abdul Said ${ }^{1, a}{ }^{*}$, Rizal hanifi' ${ }^{2, b}$, dan Oleh ${ }^{3, c}$ \\ ${ }^{1}$ Syahbana, Jl. Raya Husen Kertadibrata, RT.023/RW.10, Mulyasari, Kec. Pamanukan, \\ Kabupaten Subang, Jawa Barat 41254, \\ ${ }^{2}$ Percetakan Birulangit, Jl. Ir. Haji Juanda No.231, RT.05/RW.02 Ds, Jomin Bar., Kec. \\ Kotabaru, Kabupaten Karawang, Jawa Barat 41374, \\ ${ }^{3}$ Jl. Manunggal VII, Palumbonsari, Kec. Karawang Tim., Kabupaten Karawang, Jawa \\ Barat 40166 \\ aabdulngaji1@gmail.com, brizal.hanifi@ft.unsika.ac.id, 'oleh@staff.unsika.ac.id
}

\begin{abstract}
Abstrak
Tujuan penelitian ini adalah untuk mengetahui effisiensi kerja AC pada ruangan tertutup, dengan memperhatikan kondisi udara luar dan dalam. melihat permasalahan mesin AC selalu terjadinya gejala kebocoran refrigerant, menggunakan metode Penelitian Rumus Siklus Ideal refrigerant Kompresi Uap. Sehingga nilai Coefficient Of Per-formance diketahui. Khasus yang diambil dari penelitian bertempat pada, rumah customer dengan Menggunakan refrigerant R.12, Tekanan $(\mathrm{P} 1)=1$ bar, Temperatur $2(\mathrm{~T} 2)=-5^{\circ} \mathrm{C}$, Tekanan2 $(\mathrm{P} 2)=3$ bar, Tekanan3 $(\mathrm{P} 3)=3,5$ bar, Laju aliran yang terjadi pada sistem tersebut $(\dot{\mathrm{m}})=60 \mathrm{Psi}=4,21 \mathrm{~kg} / \mathrm{s}$. serta dengan pencarian entalpi pada setiap titik keadaan sistem di dalam siklus refrigerant. Maka hasil perhitungan analisis, mendapatkan nilai Efisiensi Co-efficient Of Performance refrigerant 0.11\%, Efisiensi Heat Pump 0,12\% \% dari system kerja Pompa, dan Back Work Ratio 9,3\%. Serta solusi diberikan penggantian refrigerant yang lebih baik, melihat data dan tahapan proses analisis sehingga dijadikan referensi pengembangan selanjutnya.
\end{abstract}

Kata kunci : Kata kunci : effisiensi kerja AC, refrigerant, entalpi

\begin{abstract}
The purpose of this study was to determine the working efficiency of the air conditioner in a closed room, taking into account the external and internal air conditions. Seeing the problem with the AC engine, there is always a refrigerant leak symptom, using the Ideal Cycle Formula Research method for Vapor Compression refrigerant. So the value of the coefficient of performance is known. Specifically taken from the research located at the customer's house using refrigerant $R .12$, Pressure $(P 1)=1$ bar, Temperature $2(T 2)=-$ $5^{\circ} \mathrm{C}$, Pressure $2(P 2)=3$ bar, Pressure $3(P 3)=3,5$ bar, The flow rate that occurs in the system $(\dot{m})=60 P s i=4.21 \mathrm{~kg} / \mathrm{s}$. as well as by finding the enthalpy at each state point of the system in the refrigerant cycle. Then the results of the analysis calculation, get the value of Co-efficient Of Performance refrigerant 0.11\%, Heat Pump Efficiency $0.12 \% \%$ of the pump working system, and Back Work Ratio 9.3\%. And the solution is given a better refrigerant replacement, looking at the data and stages of the analysis process so that it can be used as a reference for further development.
\end{abstract}

Key words : Key words : AC working efficiency, refrigerant, enthalpy 


\section{PENDAHULUAN}

Pada saat ini kemajuan di bidang ilmu pengetahuan dan teknologi sudah semakin pesat. Hal tersebut menyebabkan persaingan dalam dunia industri semakin ketat terutama dalam memenuhi kebutuhan pelanggan, perusahaan harus dapat memproduksi sesuai target dari marketing. Untuk menyikapi hal ini, perusahaan harus lebih inovatif dan mampu bersaing dengan perusahaan- perusahaan lain sebagai pesaingnya dan setiap perusahaan dituntut untuk selalu memperbaiki setiap departemen dan proses yang ada didalamnya.

Penelitian dilakukan di departemen engineering, karena pada departemen tersebut terdapat mesinmesin dan sistem yang mendukung pada proses produksi obat. Salah satunya yaitu sistem HVAC (Heating, Ventilation, and Air Condition) merupakan sistem pengkondisian udara yang saling berhubungan, karena menentukan suhu dan kelembaban udara dalam suatu ruangan. Sistem HVAC memiliki peran sangat penting bagi, kenyamanan para pengguna didalam ruangan dengan mematuhi beberapa ketentuan tertentu, Apabila sistem HVAC memiliki kendala seperti mengalami kerusakan pada salah satu part, maka proses produksi pun akan terhambat dan akan mempengaruhi kualitas udara di sekitar lingkungan.

Sistem HVAC dibagi dalam beberapa proses didalamnya, dimulai dari sistem AHU (Air Handling Unit) yaitu proses fresh air masuk ke area plenum atau mixing clamber disertai dengan return air. Setelah proses pencapuran udara tersebut dilakukan, maka udara akan melewati proses penyaringan partikel dengan efisiensi 3 $30 \%$ menggunakan prefilter.

\section{METODE PENELITIAN}

Metode penelitian yang digunakan yaitu Siklus Ideal Refrigeran Kompresi Uap dan survei pengambilan data sepesifikasi AC, guna untuk melengkapi formu-la, pada sistem tersebut. Atau bisa dilihat dari digram alir di bawah ini :

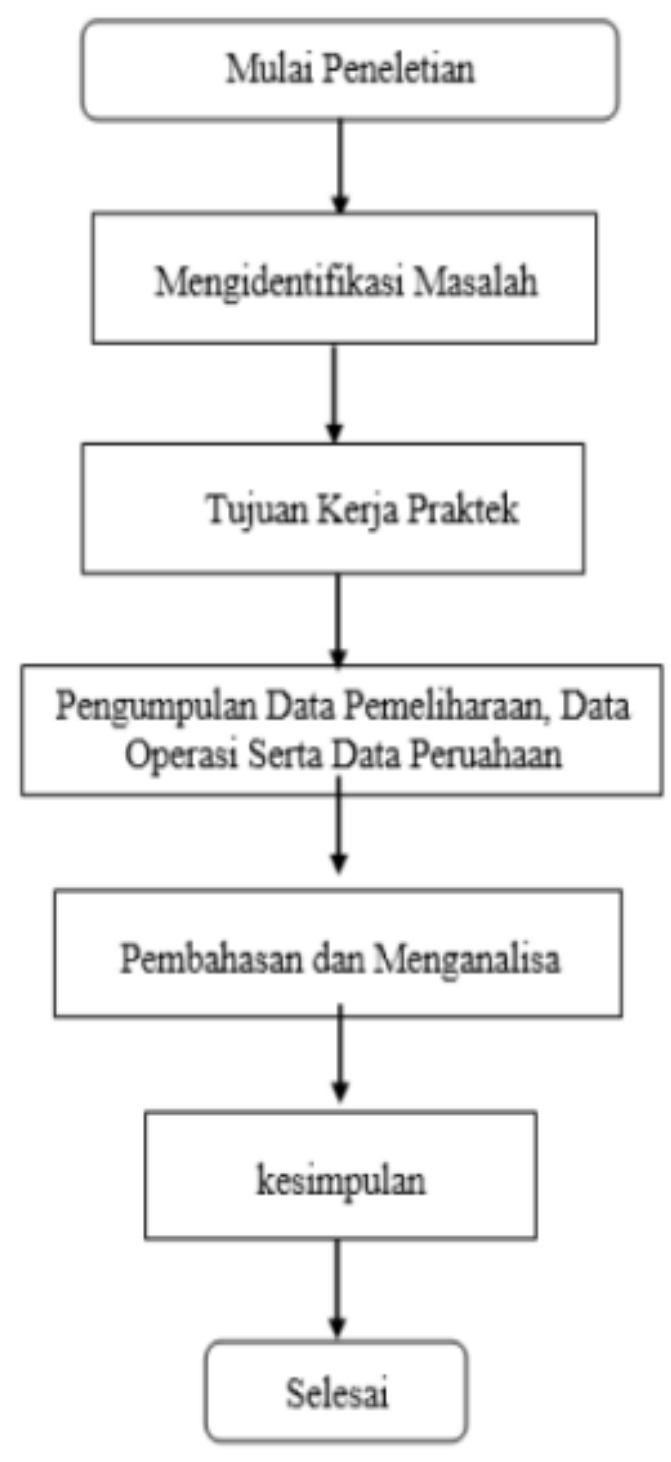

Gambar 1. Diagram penelitian

\section{HASIL DAN PEMBAHASAN}

Pengumpulan data, dari waktu pekerja dan re-frigerasi kompresi uap yang digunakan adalah jenis Tipe AC Split Wall, dan bahan refrigerasi menggunakan refrigerant 12 , dan ditahap perhitungan analisa, dengan mengambil 
sepesifikasi AC diketahui di antaranya : Menggunakan Refrigeran R.12 • Tekanan $(\mathrm{P} 1)=1$ bar - Temperatur 2 $(\mathrm{T} 2)=-5^{\circ} \mathrm{C} \cdot$ Tekanan $2(\mathrm{P} 2)=3$ bar $\bullet$ Tekanan3 $(\mathrm{P} 3)=3,5$ bar $\cdot$ Laju aliran yang terjadi pada sistem tersebut $(\dot{\mathrm{m}})=$ $60 \mathrm{Psi}=4,21 \mathrm{~kg} / \mathrm{s}$
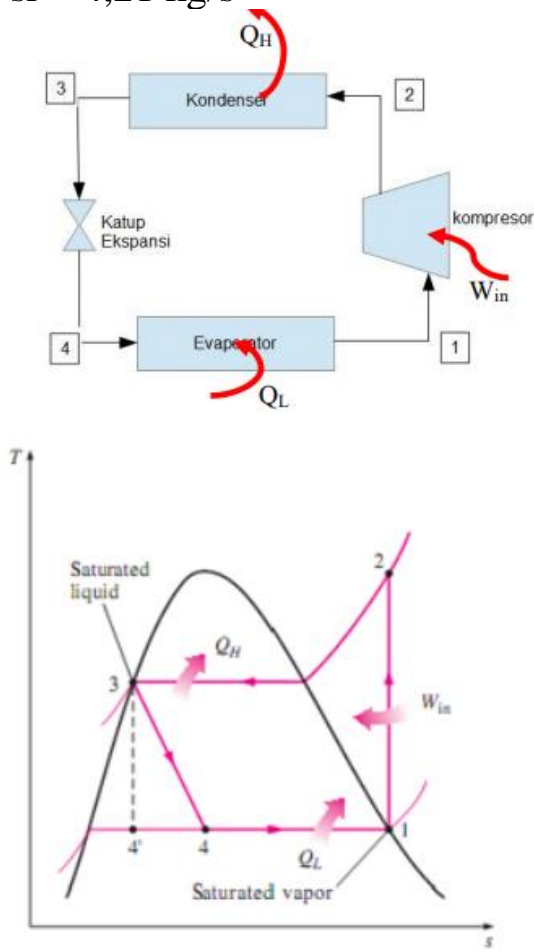

Gambar 2. Siklus ideal refrigerant kompresi uap

\section{Pencarian nilai entalpi pada setiap kondisi}

titik keadaan 1

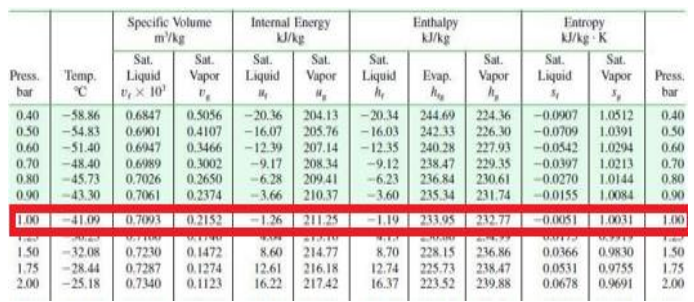

Tabel 1.sifat termodinamika freon R 12 jenuh (tabel tekanan)

Didapat tekanan $(\mathrm{P} 1)=1 \mathrm{bar}$

Sehinggad didapat dengan Enthalpy $(\mathrm{h} 1 \mathrm{atau} \mathrm{hg})=232.77 \mathrm{kj} / \mathrm{kg}$
Titik keadaaan 2

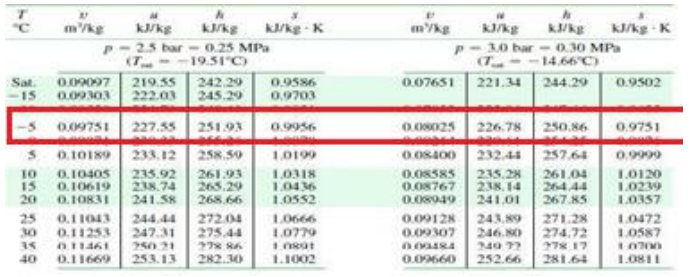

Tabel 2. Sifat Termodinamika Freon R-12 Superpanas

Tekanan1 $(\mathrm{P} 1)=3$ bar

Temperatur $2(\mathrm{~T} 2)=-5^{\circ} \mathrm{C}$

Sehingga didapat dengan Enthalpy $(\mathrm{h} 2)=250.86 \mathrm{kj} / \mathrm{kg}$

Titik Keadaan 3

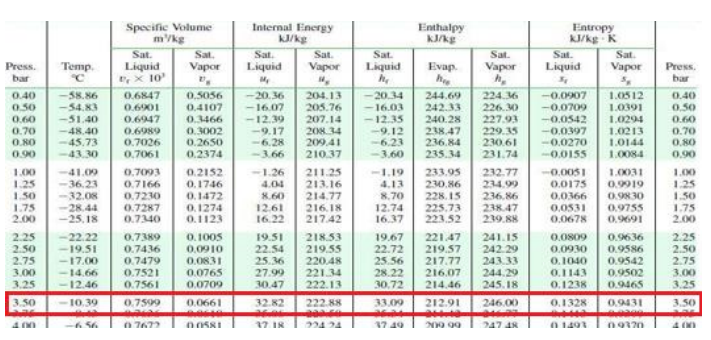

Tabel 3. Sifat Termodinamika Freon R12 Jenuh (Tabel tekanan)

Tekanan3 $(\mathrm{P} 3)=3,5$ bar

Sehingga didapat dengan Enthalpy $(\mathrm{h} 3)=33.09 \mathrm{kj} / \mathrm{kg}$

Titik keadaan 4

Berada pada Kaptup expansi. Pada komponen ini nilai entalpy pada titik tersenut sama dengan nilai entalpy sebelumnya yaitu :

h3 = h4

Sehingga didapat dengan Enthalpy $(\mathrm{h} 3=\mathrm{h} 4)=33.09 \mathrm{kj} / \mathrm{kg}$ 


\section{HASIL ANALISIS}

Proses energi yang terjadi pada setiap komponen siklus refrigeran pbisa kita lihat di bawah ini:

- Evapolator

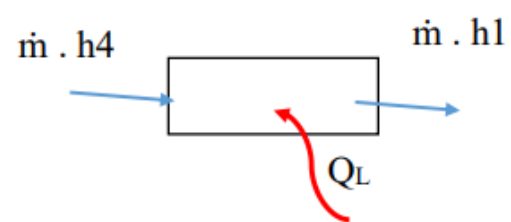

$\mathrm{QL}+(\dot{\mathrm{m}} . \mathrm{h} 4)=(\dot{\mathrm{m}} . \mathrm{h} 1) \mathrm{QL}=\dot{\mathrm{m}}(\mathrm{h} 1$. h4)

$\mathrm{QL} \quad=4,21 \mathrm{~kg} / \mathrm{s}(232.77 \mathrm{kj} / \mathrm{kg}-33.09$ $\mathrm{kj} / \mathrm{kg}$ )

$\mathrm{QL} \quad=4,21 \mathrm{~kg} / \mathrm{s}(199,68 \mathrm{kj} / \mathrm{kg})$

$\mathrm{QL} \quad=840,65 \mathrm{Kw}$

- Kompressor

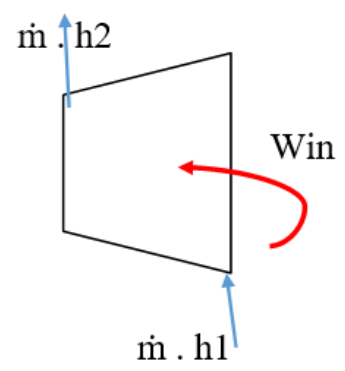

$(\dot{\mathrm{m}} \cdot \mathrm{h} 1)+\mathrm{Wc}=(\dot{\mathrm{m}} \cdot \mathrm{h} 2) \mathrm{Win}=\dot{\mathrm{m}} .(\mathrm{h} 2-$ h1)

Win $=4,21 \mathrm{~kg} / \mathrm{s} \quad(250.86 \mathrm{kj} / \mathrm{kg} \quad-$ $232.77 \mathrm{kj} / \mathrm{kg}$ )

Win $=4,21 \mathrm{~kg} / \mathrm{s}(18,09 \mathrm{kj} / \mathrm{kg}) \mathrm{c}$

Win $=76,1589 \mathrm{KW}$

- Kondensor

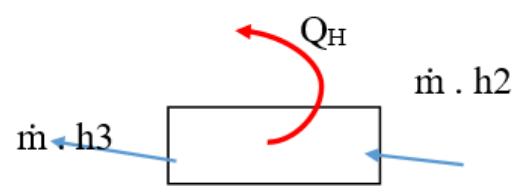

$$
\begin{aligned}
& \mathrm{QH}+(\dot{\mathrm{m}} . \mathrm{h} 3)=(\dot{\mathrm{m}} \cdot \mathrm{h} 2) \\
& \mathrm{QH}=\dot{\mathrm{m}} .(\mathrm{h} 2-\mathrm{h} 3) \\
& \mathrm{QH}=4,21 \mathrm{~kg} / \mathrm{s}(250.86 \mathrm{kj} / \mathrm{kg}-33.09 \\
& \mathrm{kj} / \mathrm{kg}) \\
& \mathrm{QH}=4,21 \mathrm{~kg} / \mathrm{s}(217.77 \mathrm{kj} / \mathrm{kg}) \\
& \mathrm{QH}=916,8117 \mathrm{Kw}
\end{aligned}
$$

- Efisiensi Energi

sehingga COP (Coefficient Of Performance) dari me-sin refrigerasi dan pompa kalor dari siklus ideal kompressi uap adalah :

sehingga nialai effisensi :

COPR (Coefficient Of Performance refrigeran) $\quad=0.11 \%$

PF (Performance Factor) $=0,12 \%$

BWR $($ Back Work Ratio $)=93 \%$.

\section{KESIMPULAN}

Setelah melaksankan Kerja Praktek di CV. Jayatama Abadi, dengan Tema Analisa Efisiensi Kerja Ac Dalam Ruangan Tertutup, maka mendapatkan beberapa kesimpulan :

1. Dengan melihat data dan tahapan proses perawatan AC maka didapat hasil analisis yang bisa di perbaiki atau di kembangkan kembali pada penelitian selanjutnya.

2. Hasil dari analisa system kerja AC dalam ruangan tertutup, mendapatkan COP $0.11 \%$, PF $0,12 \%$ dari system kerja Pompa dan BWR 9,3\%

\section{REFERENSI}

[1] Wiranto Arismunandar " Penyegaran udara",o Iskandar Danusugondo,"Dasar-dasar Teknik tata udara", o Supratman Hara, "Refrijerasi dan Pengkondisian udara", o Prihadi Setyo Darmanto,"Teknik

Pendingin", 1981

[2] Yunus A Cengel \& Michael A Boles, December"A Thermodynamics, An Engineering Ap-proach, Seventh Edition, Mc Graw Hill, New York. o L. Haar and J.S. Gallgh-er,"Thermodynamics Properties of Ammonia", 1989. 
[3] D.P. Wilsonand R.S. Basau," Thermodynamics properties of a New Stratospherically Safe Working Fluid" 1988

[4] A Kamei and S. W. Beyerlein, "A fundamental Equation for, 1992

[5] Michael J. Moran and Howard N. Shapiro." Fun-damentals of Engineering Thermodynamics, 5th Edition", John Wiley \& Sons, Canada, 2003 